\title{
Assessment of the benefits of head-up preoxygenation using near-infrared spectroscopy with pulse oximetry in a swine model
}

\author{
Tadayoshi Kurita $^{1} \cdot$ Shingo Kawashima ${ }^{1} \cdot$ Koji Morita $^{1} \cdot$ Yoshiki Nakajima $^{1}$
}

Received: 23 October 2019 / Accepted: 31 December 2019 / Published online: 2 January 2020

(c) Springer Nature B.V. 2020

\begin{abstract}
Compared with supine positioning, head-up positioning improves preoxygenation and prolongs the time to oxygen desaturation. We reevaluated benefits of head-up positioning using near-infrared spectroscopy (NIRS) with pulse oximetry in a pig model. Six pigs (mean \pm SD weight: $25.3 \pm 0.6 \mathrm{~kg}$ ) were anesthetized with isoflurane and evaluated in four positions-supine, head-up, head-down, head-up to supine-just before apnea (positions' order after "supine" was randomized). In each position, after 5 min of preoxygenation with $100 \%$ oxygen, apnea was induced and the time to $\mathrm{SpO}_{2}<70 \%$ measured. Hemodynamic and blood-gas variables and the cerebral tissue oxygenation index (TOI) were evaluated using NIRS and recorded. Hypovolemia was induced by collecting $600 \mathrm{~mL}$ blood. Apnea experiment was performed again in each position. The times (seconds) $\pm \mathrm{SD}$ to $\mathrm{SpO}_{2}<70 \%$ were $108 \pm 13$ (supine), $138 \pm 15$ (head-up; $\mathrm{P}<0.0001$ vs all other positions); $101 \pm 12$ (headdown) and $106 \pm 15$ (head-up to supine) during normovolemia, and 110 $\pm 29,120 \pm 7$ (not significant vs all other positions), $101 \pm 16$, and $106 \pm 11$, respectively, during hypovolemia. Although the TOI was not associated with the positions during normovolemia, the head-up position during hypovolemia decreased TOI from $62 \% \pm 6 \%$ (supine) to $50 \% \pm 9 \%$ (head-up; $\mathrm{P}=0.0019$ ) before preoxygenation, and it remained low during apnea. The head-up position improves preoxygenation, but repositioning to supine negates the benefits. Head-up positioning during evident hypovolemia should be avoided because the cerebral oxygenation could decrease.
\end{abstract}

Keywords Apneic desaturation · Cerebral oxygenation $\cdot$ Head-up tilt $\cdot$ Hypovolemia $\cdot$ Near-infrared spectroscopy $\cdot$ Patient positioning

\section{Introduction}

Critical care patients frequently require emergency tracheal intubation, which usually involves preoxygenation, rapidsequence induction, and subsequent intubation without intervening mask ventilation $[1,2]$. Although adequate preoxygenation theoretically increases oxygen reserves by approximately 2.5 -fold before preoxygenation [3], the duration of apnea tolerance is shortened when oxygen storage is low because of decreased functional residual capacity (FRC), low alveolar fraction of oxygen, and/or high oxygen consumption $\left(\mathrm{VO}_{2}\right)[3]$.

Tadayoshi Kurita

tadkur@hama-med.ac.jp

1 Department of Anesthesiology and Intensive Care,

Hamamatsu University School of Medicine, 1-20-1

Handayama, Hamamatsu 431-3192, Japan
Previous studies have demonstrated that, compared with the supine position, the $20^{\circ}-25^{\circ}$ head-up position improves preoxygenation and prolongs the apneic desaturation time, even in nonobese patients [4-7], because the head-up position increases the FRC [3, 8]. After preoxygenation, however, patients may be returned to the supine position because it is most familiar to anesthesiologists for tracheal intubation although this position change may negate the increased FRC benefits [8] and shorten the apneic desaturation time [9].

Patients requiring emergency tracheal intubation frequently suffer from major bleeding and/or hypovolemia. The head-down position is advantageous for increasing the preload despite decreasing the FRC, whereas the head-up position decreases preload despite high oxygen storage and might decrease cerebral tissue oxygenation [10]. The efficacy of positioning for maintaining oxygenation after preoxygenation has not been examined during hypovolemia or when using cerebral oxygenation. In fact, pulse oximetry oxyhemoglobin saturation $\left(\mathrm{SpO}_{2}\right)$ does not reflect changes 
in cerebral oxygenation and so could not be used to evaluate apnea tolerance in the cerebrum [11-13].

We conducted the present study to investigate the effect of four positions (supine, head-up, head-down, repositioning from head-up to supine after preoxygenation) on the time until $\mathrm{SpO}_{2}$ reaches $<70 \%$ and cerebral tissue oxygenation using near-infrared spectroscopy (NIRS) under normovolemic and hypovolemic conditions in a pig model.

We hypothesized that (1) the head-up position prolongs the time to oxygen desaturation, but repositioning from the head-up to supine position after preoxygenation completely negates the benefits of the head-up position, and (2) the head-up position during hypovolemia is harmful because cerebral oxygenation decreases regardless of high oxygen storage, which is not detected by conventional pulse oximetry.

\section{Methods}

\subsection{Animal preparation}

The Ethics Committee of the Animal Research Division at Hamamatsu University School of Medicine approved this study (Approval Number 2019001; provided on 15 February 2019). This study was performed in accordance with the International Association of Veterinary Editors' Consensus Author Guidelines on Animal Ethics and Welfare.

Six pigs (body weight: range $24.6-26.3 \mathrm{~kg}$, mean $\pm \mathrm{SD}$ $25.3 \pm 0.6 \mathrm{~kg}$ ) were included in this study. General anesthesia was induced by isoflurane inhalation (5\%) in oxygen at $3 \mathrm{~L} / \mathrm{min}$ using a standard animal face mask with each pig in the supine position. After tracheostomy with regional anesthesia, anesthesia was maintained with $2.5 \%$ inhaled isoflurane and a $1: 1 \mathrm{~L} / \mathrm{min}$ oxygen-air mixture [fraction of inspired oxygen $\left(\mathrm{FiO}_{2}\right)$ of 0.6 ] via mechanical ventilation. We did not use positive end-expiratory pressure in this study. End-tidal partial pressure of carbon dioxide was set at $40-45 \mathrm{mmHg}$ during animal preparation, and this ventilator setting was maintained throughout the study. A lead II electrocardiogram was monitored with three cutaneous electrodes, and pulse oximetry was monitored with a sensor (LNCS sensor; Masimo, Tokyo, Japan) positioned on the shaved left ear. The right jugular vein was cannulated with a 14-gauge double-lumen catheter and a 5-F pulmonary arterial catheter (Nihon Kohden, Tokyo, Japan), and the right femoral artery was cannulated with a 16-gauge catheter. All catheters were placed under local anesthesia after inducing general anesthesia. We infused saline $100 \mathrm{~mL} / \mathrm{h}$ for maintenance intravenous fluids during the study. Body temperature was maintained throughout the study with an electric heater and air conditioning.
After these preparation steps, the parietal scalp was widely removed to avoid contamination by extracranial blood [14-17], and a NIRO ${ }^{\circledR}$ probe (NIRO-200; Hamamatsu Photonics, Hamamatsu, Japan) was placed on the center of the parietal skull (bone thickness in this region is $5 \mathrm{~mm}$, and the sagittal sinus is $2-3 \mathrm{~mm}$ for a $25-\mathrm{kg}$ pig, based on computed tomography and dissection in our pilot studies). The probe, which consists of the emitter and receiver, is fixed in a rubber holder to ensure an emitter-receiver distance of $30 \mathrm{~mm}$. Hence, we measured the oxygenation of the cerebrum at an approximately $20(\approx 30 \times 0.7) \mathrm{mm}$ depth from the skull. Tissue oxygenation indices (TOIs) were monitored at 1-s intervals using spatially resolved spectroscopy. Details of the NIRO-200 have been explained previously [18-20].

\subsection{Experimental protocol}

Following animal preparation in the supine position, the $1: 1 \mathrm{~L} / \mathrm{min}$ inspiratory oxygen-air mixture $\left(\mathrm{FiO}_{2} 0.6\right)$ was changed to $100 \%$ oxygen at $2 \mathrm{~L} / \mathrm{min}\left(\mathrm{FiO}_{2} 1.0\right)$ for $5 \mathrm{~min}$ (preoxygenation). Four minutes after changing the fraction of inspired oxygen, $20 \mathrm{mg}$ of rocuronium bromide was administered to prevent spontaneous breathing. After $5 \mathrm{~min}$ of preoxygenation, apnea was induced by disconnecting the pigs from the ventilator. The time until $\mathrm{SpO}_{2}$ reached $<70 \%$ was then measured (primary endpoint). After meeting this criterion, mechanical ventilation with $100 \%$ oxygen was restarted for $5 \mathrm{~min}$, after which the inspiratory gas mixture was returned to the baseline oxygen-air mixture of $1: 1 \mathrm{~L} /$ $\min$.

After the apnea experiment in the supine position, subsequent pig positions were changed to each of three positions, in the following order: (1) $20^{\circ}$ head-up position (head-up); (2) $20^{\circ}$ head-down position (head-down); (3) $20^{\circ}$ head-up during preoxygenation, with immediate repositioning to supine just before disconnecting from the ventilator (head-up to supine). The three positions' order was randomly assigned to one of six patterns by drawing lots, and then the next pig was randomly assigned to one of the remaining patterns. Thus, six pigs were included in this study. After each apnea experiment, we returned each pig to the supine position for $5 \mathrm{~min}$ and then changed to the next position for $20 \mathrm{~min}$. We did not provide for any recruitment maneuvers in the lungs during experiments. After the pig's hemodynamic parameters and cerebral tissue oxygenation stabilized, preoxygenation was restarted, and the apnea experiment was performed in each position as described above.

To induce the hypovolemic condition, we removed $600 \mathrm{~mL}$ of blood (approximately 33\% of the pig's estimated total blood volume) via an arterial catheter. After the pig's hemodynamic parameters stabilized, 5 min of preoxygenation was initiated, and the apnea experiment was performed again and repeated in each position as described previously. 
The order of the body position was matched to the order during the normovolemic condition in each animal.

Heart rate (HR), mean arterial pressure (MAP), and cerebral tissue oxygenation index (TOI) were recorded, and arterial blood gases were measured before and after preoxygenation, at 30 and $60 \mathrm{~s}$ after the start of apnea, and at $\mathrm{SpO}_{2}<70 \%$. Cardiac output (CO), hematocrit, and mixed venous blood gases were measured before preoxygenation. $\mathrm{CO}$ was determined via thermodilution (Cardiac Output Computer, MTC6210; Nihon Kohden) using $5 \mathrm{~mL}$ of cold $5 \%$ glucose injected into the right atrium. Arterial oxygen content $\left(\mathrm{CaO}_{2}\right)$, mixed venous oxygen content $\left(\mathrm{CvO}_{2}\right)$, oxygen delivery $\left(\mathrm{DO}_{2}\right)$, and $\mathrm{VO}_{2}$ before apnea were then calculated.

\subsection{Statistical analysis}

Data are expressed as mean \pm SD. Statistical analysis was performed using StatView 5.0 for Windows (Abacus Concepts, Berkeley, CA, USA). HR, MAP, CO, arterial carbon dioxide partial pressure $\left(\mathrm{PaCO}_{2}\right)$, arterial oxygen partial pressure $\left(\mathrm{PaO}_{2}\right)$, hematocrit, $\mathrm{CaO}_{2}, \mathrm{CvO}_{2}, \mathrm{DO}_{2}$, and $\mathrm{VO}_{2}$ before apnea for each position were analyzed by repeatedmeasures one-way analysis of variance (ANOVA). HR, MAP, $\mathrm{PaCO}_{2}, \mathrm{PaO}_{2}$, arterial hemoglobin oxygen saturation $\left(\mathrm{SaO}_{2}\right)$, and cerebral TOI for each time point during apnea and for each position at the same time point were analyzed by repeated-measures ANOVA. The apneic desaturation time for each position was also analyzed by repeated-measures one-way ANOVA. If the ANOVA results were significant, we used the Scheffe F-test for multiple comparisons. Each variable during normovolemia was compared with that during hypovolemia via a paired $t$ test. P values and/or $95 \%$ confidence intervals (CIs) were reported. A value of $\mathrm{P}<0.05$ was considered to indicate statistical significance.

\section{Results}

Mean values for hemodynamic, blood gases, and metabolic variables before apnea in each position are shown in Table 1 . $\mathrm{PaO}_{2}$ levels before apnea were higher in both head-up and head-up to supine positions than in the supine position but did not differ significantly after $5 \mathrm{~min}$ of preoxygenation with $100 \%$ oxygen. Hypovolemia increased the HR and decreased MAP, $\mathrm{CO}, \mathrm{CvO}_{2}$, and $\mathrm{DO}_{2}$. The HR, MAP, $\mathrm{PaCO}_{2}$, and $\mathrm{PaO}_{2}$ during the apnea experiments in each position are shown in Table 2. Preoxygenation with $100 \%$ oxygen increased $\mathrm{PaO}_{2}$, and apnea decreased $\mathrm{PaO}_{2}$ and increased $\mathrm{PaCO}_{2}$. In both normovolemia and hypovolemia, $\mathrm{PaO}_{2}$ during apnea after $30 \mathrm{~s}$ was higher in the head-up position than in the supine position, and $\mathrm{PaO}_{2}$ during apnea after $60 \mathrm{~s}$ was higher in the head-up position than in all other positions.
The $\mathrm{SpO}_{2}<70 \%$ time (seconds) in each position during normovolemia was $108 \pm 13$ (supine), $138 \pm 15$ (head-up), $101 \pm 12$ (head-down), and $106 \pm 15$ (head-up to supine) (Fig. 1). The mean (95\% CI) differences for $\mathrm{SpO}_{2}<70 \%$ time between the head-up position and the supine, headdown, or head-up to supine positions, were 29 (21 to 38), $\mathrm{P}<0.0001 ; 37$ (28 to 46 ), $\mathrm{P}<0.0001$; and 32 (26 to 38 ), $\mathrm{P}<0.0001$, respectively. The head-up position during normovolemia significantly prolonged the time to $\mathrm{SpO}_{2}<70 \%$ compared with the other positions. During hypovolemia, the $\mathrm{SpO}_{2}<70 \%$ times (seconds) were $110 \pm 29$ (supine), $120 \pm 7$ (head-up), $101 \pm 16$ (head-down), and $106 \pm 11$ (head-up to supine). The mean (95\% CI) differences in the time to $\mathrm{SpO}_{2}<70 \%$ between the head-up position and each other position were 11 ( -11 to 33 ), $\mathrm{P}=0.60 ; 19$ (10 to 28 ), $\mathrm{P}=0.16$; and 15 (4 to 25 ), $\mathrm{P}=0.36$, respectively. The time to $\mathrm{SpO}_{2}<70 \%$ in the head-up position decreased significantly during hypovolemia $(\mathrm{P}=0.02)$, and hypovolemia decreased the effect of the head-up position on prolonging the time to desaturation.

Changes in $\mathrm{SaO}_{2}$ during apnea are shown in Fig. 2. During normovolemia, $\mathrm{SaO}_{2}$ at $\mathrm{FiO}_{2} 0.6$ were $100 \pm 0$ (supine), $100 \pm 0$ (head-up), $100 \pm 0$ (head-down), and $100 \pm 0$ (headup to supine) $(\mathrm{P}=0.99) ; 100 \pm 0,100 \pm 0,100 \pm 0$, and $100 \pm 0$ at $\mathrm{FiO}_{2} 1.0(\mathrm{P}=0.99) ; 99 \pm 1,100 \pm 0,99 \pm 1$, and $100 \pm 0$ at apnea $30 \mathrm{~s}(\mathrm{P}=0.31) ; 92 \pm 7,98 \pm 2,91 \pm 8$, and $90 \pm 6$ at apnea $60 \mathrm{~s}(\mathrm{P}=0.0016)$; and $56 \pm 3,59 \pm 3,59 \pm 3$, and $56 \pm 2$ at $\mathrm{SpO}_{2}<70 \%(\mathrm{P}=0.19)$, respectively. $\mathrm{SaO}_{2}$ at apnea $60 \mathrm{~s}$ in the head-up was significantly higher than those in all other positions. During hypovolemia, $\mathrm{SaO}_{2}$ at $\mathrm{FiO}_{2}$ 0.6 were $100 \pm 0$ (supine), $100 \pm 0$ (head-up), $100 \pm 0$ (headdown), and $100 \pm 0$ (head-up to supine) $(\mathrm{P}=0.99) ; 100 \pm 0$, $100 \pm 0,100 \pm 0$, and $100 \pm 0$ at $\mathrm{FiO}_{2} 1.0(\mathrm{P}=0.99) ; 100 \pm 0$, $100 \pm 0,100 \pm 0$, and $100 \pm 0$ at apnea $30 \mathrm{~s}(\mathrm{P}=0.99) ; 89 \pm 9$, $98 \pm 2,90 \pm 4$, and $92 \pm 4$ at apnea $60 \mathrm{~s}(\mathrm{P}=0.03)$; and $57 \pm 4,63 \pm 7,61 \pm 7$, and $58 \pm 3$ at $\mathrm{SpO}_{2}<70 \%(\mathrm{P}=0.23)$, respectively. $\mathrm{SaO}_{2}$ at apnea $60 \mathrm{~s}$ in the head-up position was significantly higher than that in the supine position. Each $\mathrm{SaO}_{2}$ at each time point in each position did not significantly change after hypovolemia.

Changes in cerebral TOI during apnea are shown in Fig. 3. During normovolemia, cerebral TOIs at $\mathrm{FiO}_{2} 0.6$ were $68 \pm 3$ (supine), $68 \pm 6$ (head-up), $69 \pm 6$ (head-down), and $68 \pm 6$ (head-up to supine) $(\mathrm{P}=0.87) ; 71 \pm 4,68 \pm 6,70 \pm 6$, and $69 \pm 6$ at $\mathrm{FiO}_{2} 1.0(\mathrm{P}=0.37) ; 71 \pm 5,69 \pm 5,70 \pm 7$, and $70 \pm 6$ at apnea $30 \mathrm{~s}(\mathrm{P}=0.64) ; 67 \pm 6,69 \pm 7,65 \pm 7$, and $67 \pm 7$ at apnea $60 \mathrm{~s}(\mathrm{P}=0.08)$; and $52 \pm 6,56 \pm 9,54 \pm 8$, and $56 \pm 8$ at $\mathrm{SpO}_{2}<70 \%(\mathrm{P}=0.43)$, respectively. There were no significant differences in TOI values among the positions during normovolemia. In contrast, during hypovolemia, cerebral TOIs at $\mathrm{FiO}_{2} 0.6$ were $62 \pm 6$ (supine), $50 \pm 9$ (head-up), $61 \pm 4$ (head-down), and $50 \pm 6$ (head-up to supine) $(\mathrm{P}=0.0019) ; 62 \pm 7,50 \pm 10,61 \pm 5$, and $49 \pm 10$ 
Table 1 Hemodynamic, blood gas and metabolic variables before apnea $\left(\mathrm{FiO}_{2}=0.6\right)$ in each position

\begin{tabular}{|c|c|c|c|c|}
\hline & Supine & Head-up & Head-down & Head-up to supine \\
\hline \multicolumn{5}{|l|}{ Normovolemia $(\mathrm{n}=6)$} \\
\hline HR (beats/min) & $123 \pm 27$ & $144 \pm 34$ & $130 \pm 24$ & $140 \pm 32$ \\
\hline MAP (mmHg) & $74 \pm 8$ & $66 \pm 6$ & $69 \pm 9$ & $68 \pm 7$ \\
\hline $\mathrm{CO}(\mathrm{L} / \mathrm{min})$ & $2.8 \pm 0.5$ & $2.4 \pm 0.3$ & $3.0 \pm 0.6$ & $2.3 \pm 0.3$ \\
\hline $\mathrm{PaCO}_{2}(\mathrm{mmHg})$ & $45 \pm 4$ & $45 \pm 8$ & $46 \pm 7$ & $43 \pm 5$ \\
\hline $\mathrm{PaO}_{2}(\mathrm{mmHg})$ & $152 \pm 35$ & $190 \pm 30 *$ & $173 \pm 20$ & $191 \pm 34^{*}$ \\
\hline $\mathrm{PaO}_{2 \text { F1.0 }}(\mathrm{mmHg})$ & $255 \pm 64$ & $309 \pm 52$ & $289 \pm 36$ & $306 \pm 62$ \\
\hline Hematocrit (\%) & $31 \pm 4$ & $33 \pm 4$ & $32 \pm 4$ & $32 \pm 3$ \\
\hline $\mathrm{CaO}_{2}(\mathrm{~mL} / \mathrm{dL})$ & $13.9 \pm 2.0$ & $15.0 \pm 1.7$ & $14.3 \pm 1.6$ & $14.5 \pm 1.2$ \\
\hline $\mathrm{CvO}_{2}(\mathrm{~mL} / \mathrm{dL})$ & $9.4 \pm 1.4$ & $9.1 \pm 1.0$ & $9.5 \pm 1.5$ & $8.4 \pm 1.3$ \\
\hline $\mathrm{DO}_{2}(\mathrm{~mL} / \mathrm{min})$ & $386 \pm 77$ & $360 \pm 56$ & $436 \pm 116$ & $338 \pm 64$ \\
\hline $\mathrm{VO}_{2}(\mathrm{~mL} / \mathrm{min})$ & $122 \pm 21$ & $143 \pm 30$ & $144 \pm 44$ & $141 \pm 29$ \\
\hline \multicolumn{5}{|l|}{ Hypovolemia $(n=6)$} \\
\hline HR (beats/min) & $199 \pm 41^{\text {II }}$ & $215 \pm 35^{\mathbb{I}}$ & $198 \pm 37^{\mathbb{I}}$ & $210 \pm 37^{\mathbb{I}}$ \\
\hline MAP (mmHg) & $52 \pm 9^{\mathbb{T l}}$ & $45 \pm 11^{\text {I }}$ & $53 \pm 13$ & $42 \pm 8^{\mathbb{I I}}$ \\
\hline $\mathrm{CO}(\mathrm{L} / \mathrm{min})$ & $1.6 \pm 0.1^{\mathbb{I}}$ & $1.4 \pm 0.2^{\mathbb{I}}$ & $2.1 \pm 0.3^{\# \Phi[}$ & $1.3 \pm 0.2^{\mathbb{I}}$ \\
\hline $\mathrm{PaCO}_{2}(\mathrm{mmHg})$ & $42 \pm 3^{\mathbb{I}}$ & $39 \pm 6$ & $44 \pm 1$ & $39 \pm 5^{\mathbb{I}}$ \\
\hline $\mathrm{PaO}_{2}(\mathrm{mmHg})$ & $152 \pm 35$ & $179 \pm 31$ & $158 \pm 11$ & $153 \pm 38$ \\
\hline $\mathrm{PaO}_{2 \text { F1.0 }}(\mathrm{mmHg})$ & $239 \pm 69$ & $305 \pm 60 *$ & $265 \pm 17$ & $263 \pm 61$ \\
\hline Hematocrit (\%) & $29 \pm 3$ & $29 \pm 5$ & $28 \pm 5$ & $28 \pm 3^{\mathbb{I}}$ \\
\hline $\mathrm{CaO}_{2}(\mathrm{~mL} / \mathrm{dL})$ & $13.0 \pm 1.3$ & $13.0 \pm 2.1$ & $12.9 \pm 2.1$ & $12.8 \pm 1.4^{\mathbb{I}}$ \\
\hline $\mathrm{CvO}_{2}(\mathrm{~mL} / \mathrm{dL})$ & $5.4 \pm 2.0^{\mathbb{q}}$ & $4.1 \pm 1.1^{\mathbb{I}}$ & $6.1 \pm 1.8^{\dagger \Uparrow \pi}$ & $3.9 \pm 1.5^{\ddagger \pi}$ \\
\hline $\mathrm{DO}_{2}(\mathrm{~mL} / \mathrm{min})$ & $210 \pm 32^{\mathbb{I}}$ & $188 \pm 54^{\mathbb{I I}}$ & $267 \pm 55^{\dagger \pi}$ & $172 \pm 40^{\ddagger \pi}$ \\
\hline $\mathrm{VO}_{2}(\mathrm{~mL} / \mathrm{min})$ & $121 \pm 17$ & $129 \pm 45$ & $140 \pm 16$ & $117 \pm 21$ \\
\hline
\end{tabular}

Data are expressed as mean values $\pm \mathrm{SD}$

$H R$ heart rate, MAP mean arterial pressure, $\mathrm{CO}$ cardiac output, $\mathrm{PaO}_{2}$ F1.0 $\mathrm{PaO}_{2}$ after ventilated by $100 \%$ oxygen for $5 \mathrm{~min}, \mathrm{CaO}_{2}$ arterial oxygen content, $\mathrm{CvO}_{2}$ mixed venous oxygen content, $\mathrm{DO}_{2}$ oxygen delivery, $\mathrm{VO}_{2}$ oxygen consumption

* Significant difference versus supine position

${ }^{\dagger}$ Significant difference versus head-up position

${ }^{\ddagger}$ Significant difference versus head-down position

\#Significant difference vs. all other conditions

${ }^{\text {II }}$ Significant difference versus during normovolemia at $\mathrm{FiO}_{2} 1.0(\mathrm{P}=0.0020) ; 59 \pm 10,49 \pm 11,60 \pm 7$, and $50 \pm 10$ at apnea $30 \mathrm{~s}(\mathrm{P}=0.0196) ; 58 \pm 10,49 \pm 10,56 \pm 6$, and $49 \pm 10$ at apnea $60 \mathrm{~s}(\mathrm{P}=0.0606)$; and $47 \pm 12,43 \pm 7$, $47 \pm 7$, and $43 \pm 8$ at $\mathrm{SpO}_{2}<70 \%(\mathrm{P}=0.4632)$, respectively. During hypovolemia, cerebral TOI before apnea $\left(\mathrm{FiO}_{2} 0.6\right.$ and $\mathrm{FiO}_{2} 1.0$ ) in the head-up and head-up to supine positions were significantly lower than those in the supine and headdown positions, an effect that tended to continue until reaching $\mathrm{SpO}_{2}<70 \%$. Each TOI at each time point in each position decreased after hypovolemia except TOIs at apnea $60 \mathrm{~s}$ and at $\mathrm{SpO}_{2}<70 \%$ in the supine and head-down positions.

The relations between cerebral TOI and $\mathrm{SaO}_{2}$ in each position during apnea are shown in Fig. 4. During normovolemia, the relations were comparable between positions. However, during hypovolemia, these relations shifted to the left in all positions, especially in the head-up and head-up to supine positions, during which we saw dramatic shifts to the left and decreased TOIs at similar $\mathrm{SaO}_{2}$ levels.

\section{Discussion}

Our results showed that the increased time to $\mathrm{SpO}_{2}<70 \%$ seen in the head-up position was completely reversed by repositioning to supine just before disconnecting the pigs from oxygen. The time also decreased during hypovolemia. In addition, the head-up position decreased cerebral oxygenation considerably during hypovolemia - in contrast to normovolemia in which cerebral oxygenation was not associated with the pigs' positions.

We saw the longest time to $\mathrm{SpO}_{2}<70 \%$ in the head-up position during normovolemia, similar to the results of 
Table 2 Heart rate (HR), mean arterial pressure (MAP), partial pressure of arterial carbon dioxide $\left(\mathrm{PaCO}_{2}\right)$ and oxygen $\left(\mathrm{PaO}_{2}\right)$ before and during apnea in each position

\begin{tabular}{|c|c|c|c|c|c|}
\hline & $\mathrm{FiO}_{2} 0.6$ & $\mathrm{FiO}_{2} 1.0$ & Apnea $30 \mathrm{~s}$ & Apnea $60 \mathrm{~s}$ & $\mathrm{SpO}_{2}<70 \%$ \\
\hline \multicolumn{6}{|l|}{ Normovolemia $(n=6)$} \\
\hline \multicolumn{6}{|l|}{ HR (beats/min) } \\
\hline Supine & $123 \pm 27$ & $117 \pm 24$ & $112 \pm 21 *$ & $111 \pm 21 *$ & $116 \pm 22$ \\
\hline Head-up & $144 \pm 34$ & $136 \pm 38$ & $130 \pm 36$ & $129 \pm 35$ & $142 \pm 33^{\prime}$ \\
\hline Head-down & $130 \pm 24$ & $127 \pm 27$ & $122 \pm 26$ & $124 \pm 27$ & $133 \pm 27^{\ddagger}$ \\
\hline Head-up to supine & $140 \pm 32$ & $133 \pm 30$ & $125 \pm 31 *$ & $125 \pm 29 *$ & $133 \pm 26$ \\
\hline \multicolumn{6}{|l|}{ MAP (mmHg) } \\
\hline Supine & $74 \pm 8$ & $70 \pm 9$ & $68 \pm 6$ & $69 \pm 6$ & $73 \pm 10$ \\
\hline Head-up & $66 \pm 6$ & $62 \pm 8$ & $62 \pm 7$ & $67 \pm 9$ & $86 \pm 9^{\#}$ \\
\hline Head-down & $69 \pm 9$ & $68 \pm 10$ & $66 \pm 10$ & $70 \pm 10$ & $80 \pm 10^{\#}$ \\
\hline Head-up to supine & $68 \pm 7$ & $62 \pm 8$ & $67 \pm 8$ & $74 \pm 10^{\dagger}$ & $81 \pm 12 * \dagger$ \\
\hline \multicolumn{6}{|l|}{$\mathrm{PaCO}_{2}(\mathrm{mmHg})$} \\
\hline Supine & $45 \pm 4$ & $44 \pm 4$ & $58 \pm 4^{\#}$ & $64 \pm 4^{\#}$ & $70 \pm 4^{\#}$ \\
\hline Head-up & $45 \pm 8$ & $44 \pm 7$ & $59 \pm 9^{\#}$ & $65 \pm 8^{\#}$ & $73 \pm 9^{\#}$ \\
\hline Head-down & $46 \pm 7$ & $45 \pm 7$ & $58 \pm 6^{\#}$ & $64 \pm 7^{\#}$ & $68 \pm 8^{\# \|}$ \\
\hline Head-up to supine & $43 \pm 5$ & $43 \pm 6$ & $59 \pm 6^{\#}$ & $64 \pm 7^{\#}$ & $70 \pm 7^{\#}$ \\
\hline \multicolumn{6}{|l|}{$\mathrm{PaO}_{2}(\mathrm{mmHg})$} \\
\hline Supine & $152 \pm 35$ & $255 \pm 64 *$ & $177 \pm 54^{\dagger}$ & $87 \pm 20^{\dagger \neq}$ & $42 \pm 2 * \hbar$ \\
\hline Head-up & $190 \pm 30^{\prime}$ & $309 \pm 52 *$ & $250 \pm 41 * \dagger$ & $125 \pm 31 * \dagger \$ \S$ & $44 \pm 2^{\#}$ \\
\hline Head-down & $173 \pm 20$ & $289 \pm 36^{*}$ & $197 \pm 53^{\dagger}$ & $84 \pm 19^{* \dagger+}$ & $43 \pm 3 * t+$ \\
\hline Head-up to supine & $191 \pm 34^{\prime}$ & $306 \pm 62 *$ & $177 \pm 37^{\dagger \|}$ & $78 \pm 16^{* \dagger}$ & $42 \pm 2 * \hbar$ \\
\hline \multicolumn{6}{|l|}{ Hypovolemia $(n=6)$} \\
\hline \multicolumn{6}{|l|}{ HR (beats/min) } \\
\hline Supine & $199 \pm 41$ & $197 \pm 40$ & $186 \pm 36^{*}$ & $187 \pm 37^{*}$ & $193 \pm 38$ \\
\hline Head-up & $215 \pm 35$ & $218 \pm 36$ & $201 \pm 34$ & $190 \pm 34 * \dagger$ & $197 \pm 29^{\dagger}$ \\
\hline Head-down & $198 \pm 37$ & $200 \pm 42$ & $185 \pm 42$ & $177 \pm 37^{\dagger}$ & $179 \pm 34$ \\
\hline Head-up to supine & $210 \pm 37$ & $207 \pm 35$ & $189 \pm 35^{*}$ & $181 \pm 34 *^{\dagger}$ & $183 \pm 30 * *^{\dagger}$ \\
\hline \multicolumn{6}{|l|}{ MAP (mmHg) } \\
\hline Supine & $52 \pm 9$ & $50 \pm 8$ & $44 \pm 6$ & $52 \pm 11$ & $64 \pm 18^{\dagger *}$ \\
\hline Head-up & $45 \pm 11$ & $43 \pm 13$ & $40 \pm 12$ & $40 \pm 10$ & $59 \pm 23$ \\
\hline Head-down & $53 \pm 13$ & $49 \pm 10$ & $43 \pm 7$ & $44 \pm 9$ & $49 \pm 15$ \\
\hline Head-up to supine & $42 \pm 8$ & $38 \pm 13$ & $41 \pm 16$ & $42 \pm 16$ & $50 \pm 20$ \\
\hline \multicolumn{6}{|l|}{$\mathrm{PaCO}_{2}(\mathrm{mmHg})$} \\
\hline Supine & $42 \pm 3$ & $43 \pm 3$ & $62 \pm 2^{\#}$ & $69 \pm 2^{\#}$ & $76 \pm 5^{\#}$ \\
\hline Head-up & $39 \pm 6$ & $39 \pm 6$ & $57 \pm 8^{\#}$ & $66 \pm 7^{\#}$ & $75 \pm 8^{\#}$ \\
\hline Head-down & $44 \pm 1$ & $43 \pm 2$ & $61 \pm 3^{\#}$ & $66 \pm 3^{\#}$ & $70 \pm 3^{\#}$ \\
\hline Head-up to supine & $39 \pm 5$ & $39 \pm 5$ & $62 \pm 5^{\#}$ & $67 \pm 5^{\#}$ & $74 \pm 6^{\#}$ \\
\hline \multicolumn{6}{|l|}{$\mathrm{PaO}_{2}(\mathrm{mmHg})$} \\
\hline Supine & $152 \pm 35$ & $239 \pm 69 *$ & $172 \pm 6$ & $83 \pm 24^{\dagger \ddagger}$ & $44 \pm 4 * \dagger$ \\
\hline Head-up & $179 \pm 31$ & $305 \pm 60 * 1$ & $249 \pm 43^{* * 1}$ & $116 \pm 16^{* \dagger * \S}$ & $48 \pm 5^{\#}$ \\
\hline Head-down & $158 \pm 11$ & $265 \pm 17 *$ & $206 \pm 20^{* \dagger}$ & $79 \pm 10^{* \dagger}$ & $48 \pm 9^{\#}$ \\
\hline Head-up to supine & $153 \pm 38$ & $263 \pm 61^{*}$ & $211 \pm 45$ & $86 \pm 16^{* \dagger *}$ & $48 \pm 4 * \dagger$ \\
\hline
\end{tabular}

Data are expressed as mean values $\pm \mathrm{SD}$

* Significant difference versus $\mathrm{FiO}_{2} 0.6$

${ }^{\dagger}$ Significant difference versus $\mathrm{FiO}_{2} 1.0$

${ }^{\ddagger}$ Significant difference versus Apnea $30 \mathrm{~s}$

\#Significant difference versus all other time points

'Significant difference versus supine position at same time point

"Significant difference versus head-up position at same time point

${ }^{\S}$ Significant difference versus all other positions at same time point 


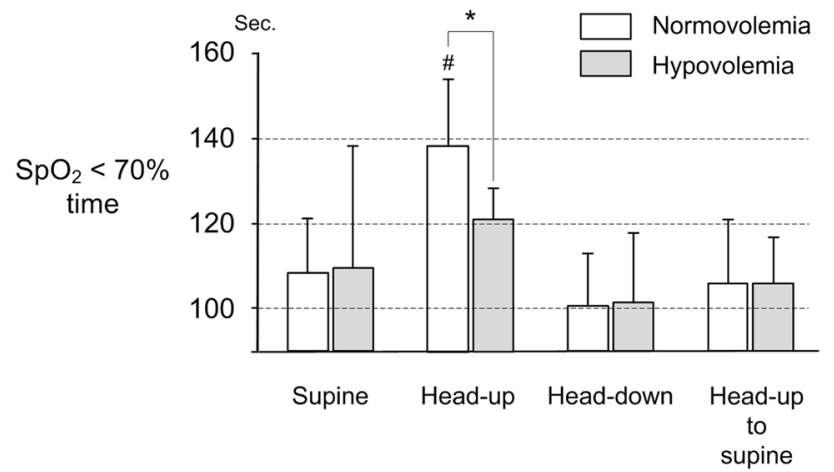

Fig. 1 Apneic desaturation time (time to pulse oximetry hemoglobin saturation $\left.\left(\mathrm{SpO}_{2}\right)<70 \%\right)$ in each position. "Significant difference versus all other positions during normovolemia $(\mathrm{P}=0.015$ versus supine; $\mathrm{P}=0.002$ versus head-down; $\mathrm{P}=0.008$ versus head-up to supine). *Significant difference $(\mathrm{P}=0.017)$ between normovolemia and hypovolemia in the head-up position

previous reports [4-7]. However, few studies have investigated the effect of repositioning to supine regarding the benefits of head-up preoxygenation [9]. Khandelwal et al. investigated the association between the intubation position and emergent tracheal intubation-related complications. They found that the back-up head-elevated position reduced airway-related complications [21]. Lee et al. reported that the $25^{\circ}$ back-up position provided a better laryngeal view than the supine position [22]. Although these findings suggested that the head-up position is more suitable for tracheal intubation than the supine position, anesthesiologists are accustomed to the supine position and may change patients to that position after head-up preoxygenation [6].

Adequate preoxygenation increases oxygen reserves in alveolar, arterial, venous, and tissue compartments. During normovolemia in our study, $\mathrm{CaO}_{2}, \mathrm{CvO}_{2}$, and $\mathrm{DO}_{2}$ did not differ among positions, suggesting that oxygen reserves in the blood and tissue compartments were comparable in all positions. Therefore, the pulmonary reserve in the FRC, which varies with body position, affected the time to $\mathrm{SpO}_{2}<70 \%$. The increased FRC that we saw during the head-up position quickly disappeared by repositioning to supine, which completely negated the prolonged time to $\mathrm{SpO}_{2}<70 \%$ obtained in the head-up position.

Although $\mathrm{PaO}_{2}$ at apnea $60 \mathrm{~s}$ was higher in the headup position than in all other positions during hypovolemia (Table 2) and $\mathrm{SaO}_{2}$ at apnea $60 \mathrm{~s}$ in the head-up position was also higher than that in the supine position (Fig. 2), it is unclear that hypovolemia decreased the effect of the head-up position on the time to desaturation. The head-up position worsened hemodynamics during hypovolemia and decreased $\mathrm{DO}_{2}$, although $\mathrm{VO}_{2}$ did not change. We speculate that the head-up position during hypovolemia increased the ventilation/perfusion ratio secondary to low perfusion
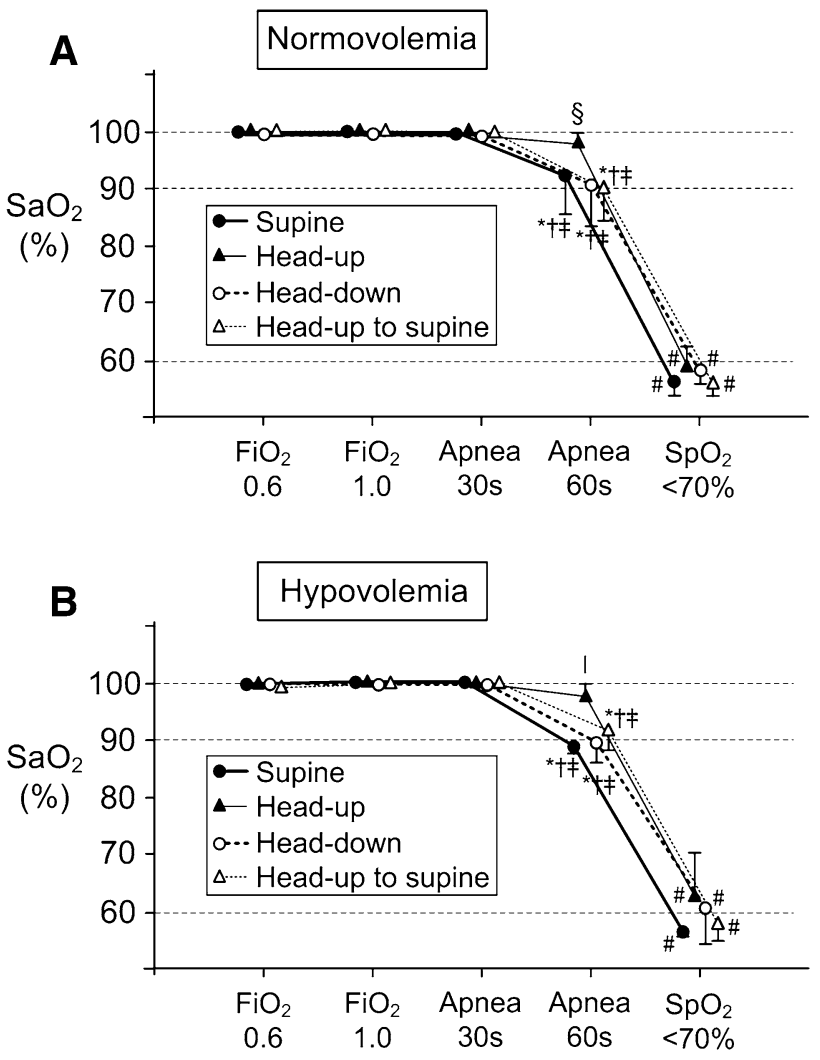

Fig. 2 Changes in arterial hemoglobin oxygen saturation $\left(\mathrm{SaO}_{2}\right)$ during the apnea experiments in each position during normovolemia (a) and hypovolemia (b). $\mathrm{FiO}_{2} \quad 0.6=$ fraction of inspired oxygen of 0.6 (before preoxygenation); $\mathrm{FiO}_{2} \quad 1.0=$ fraction of inspired oxygen of 1.0 (before starting apnea); Apnea $30 \mathrm{~s}=30 \mathrm{~s}$ after the start of apnea; Apnea $60 \mathrm{~s}=60 \mathrm{~s}$ after the start of apnea; $\mathrm{SpO}_{2}<70 \%=\mathrm{SpO}_{2}$ reaching a value of less than $70 \%$. ${ }^{*}$ Significant difference vs. $\mathrm{FiO}_{2} 0.6$ in each position [supine: $\mathrm{P}=0.0082$ and $\mathrm{P}=0.0094$ (normovolemia and hypovolemia); head-down: $\mathrm{P}=0.0043$ and $\mathrm{P}=0.0017$; head-up to supine: $\mathrm{P}<0.0001$ and $\mathrm{P}=0.0001]$. ${ }^{\dagger}$ Significant difference vs. $\mathrm{FiO}_{2}$ 1.0 in each position [supine: $\mathrm{P}=0.0050$ and $\mathrm{P}=0.0070$ (normovolemia and hypovolemia); head-down: $\mathrm{P}=0.0035$ and $\mathrm{P}=0.0015$; head-up to supine: $\mathrm{P}<0.0001$ and $\mathrm{P}<0.0001]$. ${ }^{\ddagger}$ Significant difference vs. apnea $30 \mathrm{~s}$ in each position [supine: $\mathrm{P}=0.0097$ and $\mathrm{P}=0.0076$ (normovolemia and hypovolemia); head-down: $\mathrm{P}=0.0062$ and $\mathrm{P}=0.0016$; head-up to supine: $\mathrm{P}<0.0001$ and $\mathrm{P}<0.0001]$. ${ }^{\#}$ Significant difference vs. all other time points $(\mathrm{P}<0.0001$ vs. each time point in all positions in both normovolemia and hypovolemia). 'Significant difference vs. supine position at apnea $60 \mathrm{~s}(\mathrm{P}=0.0459)$. ${ }^{\S}$ Significant difference vs. supine, head-down, and head-up to supine at apnea $60 \mathrm{~s}(\mathrm{P}=0.035, \mathrm{P}=0.0096$, and $\mathrm{P}=0.0039)$

(dead space-like effect) and, compared with normovolemia, decreased the alveolar fraction of oxygen, resulting in decreased oxygen storage after preoxygenation despite seeing no change in the increased FRC [3].

Several previous studies reporting the benefits of headup preoxygenation evaluated only the time to desaturation and/or $\mathrm{PaO}_{2}$ after preoxygenation, without investigating changes in cerebral oxygenation [4-7]. Others, however, indicated that the head-up position, even during 

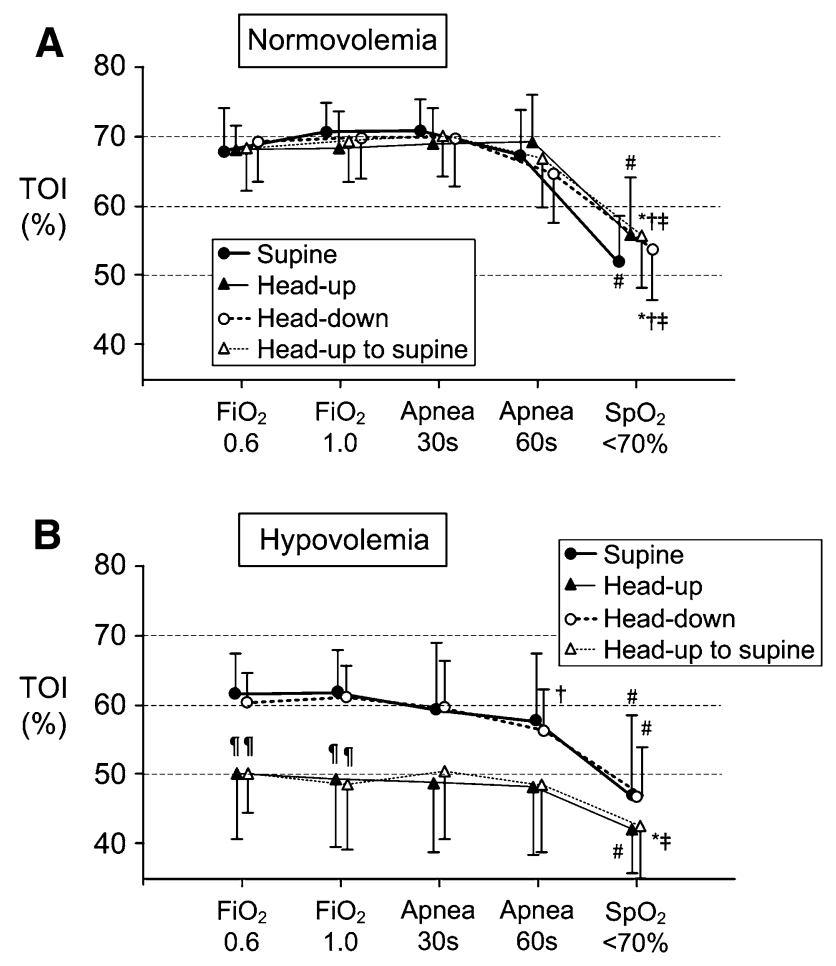

Fig. 3 Changes in the cerebral tissue oxygenation index (TOI) during the apnea experiments in each position during normovolemia (a) and hypovolemia (b). $\mathrm{FiO}_{2} \quad 0.6=$ fraction of inspired oxygen of 0.6 (before preoxygenation); $\mathrm{FiO}_{2} \quad 1.0=$ fraction of inspired oxygen of $1.0 \mathrm{~s}$ (before starting apnea); Apnea $30 \mathrm{~s}=30 \mathrm{~s}$ after the start of apnea; Apnea $60 \mathrm{~s}=60 \mathrm{~s}$ after the start of apnea; $\mathrm{SpO}_{2}<70 \%=\mathrm{SpO}_{2}$ reaching a value of $<70 \%$. ${ }^{*}$ Significant difference vs. $\mathrm{FiO}_{2} 0.6$ in each position (head-down during normovolemia: $\mathrm{P}=0.0043$; headup to supine during normovolemia and hypovolemia: $\mathrm{P}=0.0489$ and $\mathrm{P}=0.0150)$. ${ }^{\dagger}$ Significant difference vs. $\mathrm{FiO}_{2} 1.0$ in each position (head-down during normovolemia and hypovolemia: $\mathrm{P}=0.0093$ and $\mathrm{P}=0.0303$; head-up to supine during normovolemia: $\mathrm{P}=0.0319$ ). ${ }^{\ddagger}$ Significant difference vs. apnea $30 \mathrm{~s}$ in each position (head-down during normovolemia: $\mathrm{P}=0.0093$; head-up to supine during normovolemia and hypovolemia: $\mathrm{P}=0.0222$ and $\mathrm{P}=0.0126)$. "Significant difference vs. all other time points (supine during normovolemia: $\mathrm{P}=0.0005, \mathrm{P}<0.0001, \mathrm{P}<0.0001$, and $\mathrm{P}=0.0010$ vs. $\mathrm{FiO}_{2} 0.6$, $\mathrm{FiO}_{2} 1.0$, apnea $30 \mathrm{~s}$, and apnea $60 \mathrm{~s}$; head-up during normovolemia: $\mathrm{P}=0.0453, \mathrm{P}=0.00494, \mathrm{P}=0.0346$, and $\mathrm{P}=0.0316$; supine during hypovolemia: $\mathrm{P}<0.0001, \mathrm{P}<0.0001, \mathrm{P}<0.0001$, and $\mathrm{P}=0.0003$; head-up during hypovolemia: $\mathrm{P}=0.0001, \mathrm{P}=0.0003, \mathrm{P}=0.0008$, and $\mathrm{P}=0.0024$; head-down during hypovolemia: $\mathrm{P}<0.0001$ vs. all time points). ${ }^{\text {II }}$ Significant difference vs. supine and head-down positions (head-up: $\mathrm{P}=0.0202$ and $\mathrm{P}=0.0360$ at $\mathrm{FiO}_{2} 0.6$, and $\mathrm{P}=0.0305$, and $\mathrm{P}=0.0395$ at $\mathrm{FiO}_{2} 1.0$; head-up to supine: $\mathrm{P}=0.0202$ and 0.0360 at $\mathrm{FiO}_{2} 0.6$ and $\mathrm{P}=0.0198$ and $\mathrm{P}=0.0257$ at $\mathrm{FiO}_{2} 1.0$ )

normovolemia, decreased cerebral oxygenation in animals [10] and healthy adult humans [23]. The present study has uniquely evaluated the benefits of head-up preoxygenation during normal and hypovolemic conditions using both pulse oximetry and NIRS. Furthermore, in our study, the parietal scalp was removed to exclude contamination of scalp blood flow [14-17], which is a limitation of NIRS. This maneuver
A

Normovolemia
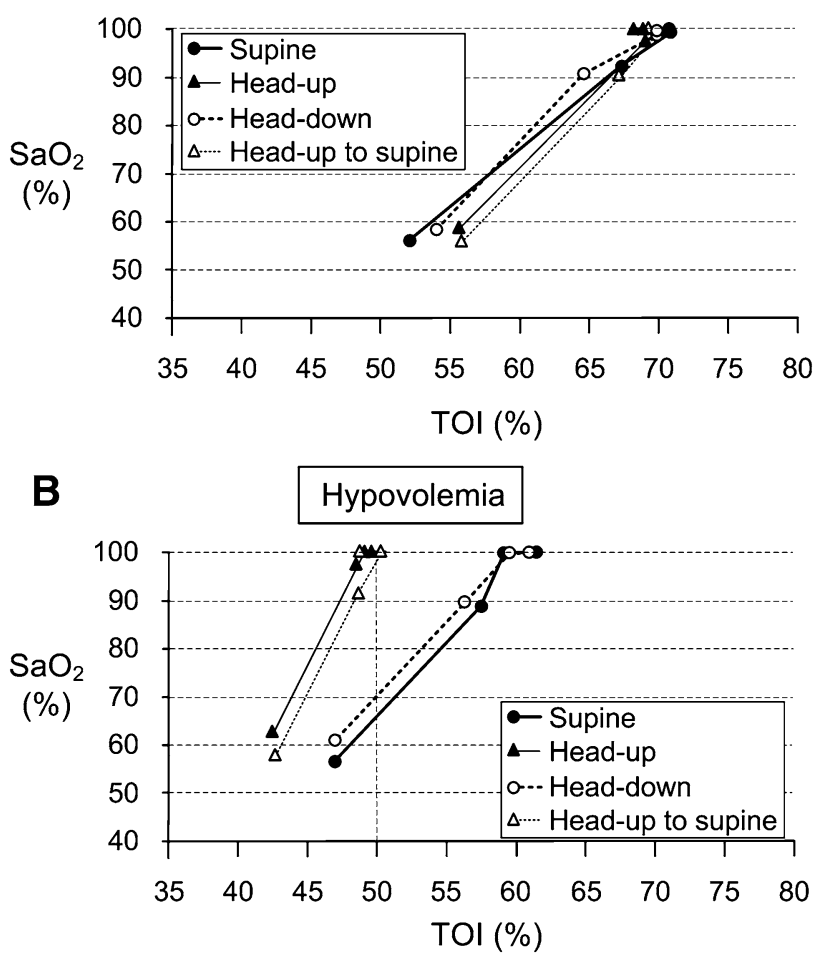

Fig. 4 Relations between cerebral tissue oxygenation index (TOI) and arterial hemoglobin oxygen saturation $\left(\mathrm{SaO}_{2}\right)$ in each position during normovolemia (a) and hypovolemia (b). The lines denote the following: after preoxygenation $\left(\mathrm{FiO}_{2} 1.0\right), 30 \mathrm{~s}$ after apnea (Apnea $30 \mathrm{~s}$ ), $60 \mathrm{~s}$ after apnea (Apnea $60 \mathrm{~s}$ ), and $\mathrm{SpO}_{2}<70 \%$. We omitted the error bars and significance indicators because this information is shown in Figs. 2 and 3

allowed us to provide accurate cerebral oxygenation values using NIRS. If the present study had evaluated only the time to desaturation and/or $\mathrm{PaO}_{2}$ after preoxygenation, similar to previous studies, the demerit of the head-up position during hypovolemia could not be identified.

During normovolemia, the relations between TOI and $\mathrm{SaO}_{2}$ were comparable among the positions (Fig. 4a). During hypovolemia, however, each TOI significantly decreased and, especially in the head-up and head-up to supine positions, shifted the relation to the left at similar $\mathrm{SaO}_{2}$ levels (Fig. 4b). Specifically, TOI values in the headup and head-up to supine positions during hypovolemia were approximately $50 \%$ at $100 \%$ of $\mathrm{SaO}_{2}$, which were similar to the TOI values in the supine and head-down positions at $<70 \%$ of $\mathrm{SaO}_{2}$. This deterioration in cerebral oxygenation could not be identified by $\mathrm{SaO}_{2}$ (Fig. 2b) and/or $\mathrm{SpO}_{2}$ values. TOI did not recover even when the head-up position was changed to supine just before apnea. Caregivers should consider that the head-up position during hypovolemia can reduce cerebral oxygenation. We previously showed that acute anemia (hemorrhage and 
subsequent fluid resuscitation) and/or $\beta 1$-blocker administration also shifted the relation between TOI and $\mathrm{SaO}_{2}$ to the left, and reduced cerebral tolerance for hypoxia [12]. The effect is substantially enhanced by $\beta 1$-blocker administration during acute anemia, and this phenomenon is thought to partly explain why $\beta$-blockers can increase the incidence of stroke under acute hemodilution during the perioperative period. In contrast, dobutamine, a $\beta 1$-stimulant, increased cerebral tolerance for hypoxia and/or anemia [13]. These alterations of cerebral tolerance could not be identified with arterial blood oxygenation. On the basis of these findings, we recommend NIRS monitoring at 1-s intervals along with pulse oximetry for emergent tracheal intubation in critical care patients. Cerebral NIRS, which estimates the oxygen supply/demand balance, might predict individual apneic tolerance better than the desaturation time.

Several limitations of this study must be noted. First, we used the apneic desaturation time in the first supine position as a reference for comparisons with results in the other positions, whereas interpreting the data may have been more reliable if we had included a time control group with no changes in the pigs' position. Furthermore, we induced apnea by disconnecting them from the ventilator after $5 \mathrm{~min}$ of $100 \%$ oxygen ventilation. This state, however, might not represent clinical preoxygenation, which typically includes the non-ventilated, but oxygen-diffusion, duration via face mask. In addition, the time to $\mathrm{SpO}_{2}<70 \%$ after $100 \%$ oxygen preoxygenation for 5 min was only 100-140 $\mathrm{s}$ in our animals, which is shorter than the expected time in adult humans [24]. The $\mathrm{VO}_{2}$ of the pigs in our study, which were approximately 2 months old, was approximately $170 \mathrm{~mL} /$ $\mathrm{min} / \mathrm{m}^{2}$ at baseline before apnea occurred (the pigs' mean body surface area was $0.77 \mathrm{~m}^{2}$, calculated by body weight [25]), which is equivalent to the $\mathrm{VO}_{2}$ of a human infant. Although the size of the oxygen reservoir in the lungs and/ or FRC might be small in pigs, high $\mathrm{VO}_{2}$ is likely to be the main reason for the early decrease in $\mathrm{SpO}_{2}$. Therefore, our findings should not be directly extrapolated to adult human patients. Finally, although changes in time to $\mathrm{SpO}_{2}<70 \%$ and/or TOI secondary to the position changes were evident, and the order of the pigs' positions was randomized, the number of study animals was small. Larger, human studies are needed to clarify our findings.

In conclusion, the head-up position improves preoxygenation and should not be changed to supine after preoxygenation. The head-up position should be retained during tracheal intubation. Although the effects of postural changes on cerebral oxygenation are minimal under normal circulatory volume, under evident hypovolemia the head-up position can decrease cerebral oxygenation, which is not detected by conventional pulse oximetry. Thus, head-up preoxygenation might be harmful in these patients.
Acknowledgements We thank Jane Charbonneau, from Edanz Group (www.edanzediting.com/ac) for editing a draft of this manuscript.

Author contributions Tadayoshi Kurita contributed to the study design, data collection, analysis of data, and manuscript preparation. Shingo Kawashima contributed to the study design and data collection. Koji Morita contributed to the data collection and analysis of data. Yoshiki Nakajima contributed to the study design. The first and revised drafts of the manuscript were written by Tadayoshi Kurita, and all authors read and approved the final manuscript.

Funding Support was provided solely from institutional and/or departmental sources.

\section{Compliance with ethical standards}

Conflict of interest The authors declare that they have no conflict of interest.

Ethical approval All procedures performed in studies involving animals were in accordance with the ethical standards of the institution at which the studies were conducted (The Committee of the Animal Research Division at Hamamatsu University School of Medicine, Approval Number 2019001). This article does not contain any studies with human participants performed by any of the authors.

\section{References}

1. Morris J, Cook TM. Rapid sequence induction: a national survey of practice. Anaesthesia. 2001;56:1090-7.

2. Warner MA, Warner ME, Weber JG. Clinical significance of pulmonary aspiration during the perioperative period. Anesthesiology. 1993;78:56-62.

3. Bouroche G, Bourgain JL. Preoxygenation and general anesthesia: a review. Minerva Anestesiol. 2015;81:910-20.

4. Lane S, Saunders D, Schofield A, Padmanabhan R, Hildreth A, Laws D. A prospective, randomized controlled trial comparing the efficacy of pre-oxygenation in the $20^{\circ}$ head-up vs supine position. Anaesthesia. 2005;60:1064-7.

5. Ramkumar V, Umesh G, Philip FA. Preoxygenation with $20^{\circ}$ head-up tilt provides longer duration of non-hypoxic apnea than conventional preoxygenation in non-obese healthy adults. $\mathbf{J}$ Anesth. 2011;25:189-94.

6. Dixon BJ, Dixon JB, Carden JR, Burn AJ, Schachter LM, Playfair JM, Laurie CP, O'Brien PE. Preoxygenation is more effective in the 25 head-up position than in the supine position in severely obese patients. Anesthesiology. 2005;102:1110-5.

7. Altermatt FR, Muñoz HR, Delfino AE, Cortínez LI. Pre-oxygenation in the obese patient: effects of position on tolerance to apnoea. Br J Anaesth. 2005;95:706-9.

8. Couture EJ, Provencher S, Somma J, Lellouche F, Marceau S, Bussières JS. Effect of position and positive pressure ventilation on functional residual capacity in morbidly obese patients: a randomized trial. Can J Anaesth. 2018;65:522-8.

9. Wax DB. Mechanism of benefit of head-up preoxygenation in obese patients. Anesthesiology. 2006;104:381.

10. Mlcek M, Belohlavek J, Huptych M, Boucek T, Belza T, Lacko S, Krupickova P, Hrachovina M, Popkova M, Neuzil P, Kittnar $\mathrm{O}$. Head-up tilt rapidly compromises hemodynamics in healthy anesthetized swine. Physiol Res. 2015;64:S677-83.

11. Kurita T, Morita K, Sato S. The influence of hypovolemia and fluid resuscitation during hemorrhagic shock on apneic oxygen 
desaturation after preoxygenation in a swine model. Anesth Analg. 2015;121:1555-61.

12. Kurita T, Morita K, Sato S. Impact of a $\beta$-blocker and/or acute hemodilution on cerebral oxygenation during apneic hypoxia. Acta Anaesthesiol Scand. 2016;60:343-53.

13. Kurita T, Kawashima S, Morita K, Nakajima Y. Dobutamine, a $\beta 1$ adrenoceptor agonist, increases cerebral oxygenation during acute anemia and apneic hypoxia. Neurocrit Care. 2017;27:420-9.

14. Davie SN, Grocott HP. Impact of extracranial contamination on regional cerebral oxygen saturation: a comparison of three cerebral oximetry technologies. Anesthesiology. 2012;116:834-40.

15. Ogoh S, Sato K, Okazaki K, Miyamoto T, Secher F, Sørensen H, Rasmussen P, Secher NH. A decrease in spatially resolved nearinfrared spectroscopy-determined frontal lobe tissue oxygenation by phenylephrine reflects reduced skin blood flow. Anesth Analg. 2014;118:823-9.

16. Sørensen H, Rasmussen P, Sato K, Persson S, Olesen ND, Nielsen HB, Olsen NV, Ogoh S, Secher MH. External carotid artery flow maintains near infrared spectroscopy-determined frontal lobe oxygenation during ephedrine administration. Br J Anaesth. 2014;113:452-9.

17. Sørensen H, Rasmussen P, Siebenmann C, Zaar M, Hvidtfeldt M, Ogoh S, Sato K, Kohl-Bareis M, Secher MH, Lundby C. Extracerebral oxygenation influence on near-infrared-spectroscopydetermined frontal lobe oxygenation in healthy volunteers: a comparison between INVOS-4100 and NIRO-200NX. Clin Physiol Funct Imaging. 2015;35:177-84.

18. Matcher SJ, Cooper CE. Absolute quantification of deoxyhaemoglobin concentration in tissue near infrared spectroscopy. Phys Med Biol. 1994;39:1295-312.
19. Suzuki S, Takasaki S, Ozaki T, Kobayashi Y. Tissue oxygenation monitor using NIR spatially resolved spectroscopy. Proc SPIE. 1999;3597:582-92.

20. Kurita T, Morita K, Sato S. Evaluation of near infrared spectroscopy for detecting the $\beta$ blocker-induced decrease in cerebral oxygenation during hemodilution in a swine model. J Clin Monit Comput. 2015;29:779-88.

21. Khandelwal N, Khorsand S, Mitchell SH, Joffe AM. Head-elevated patient positioning decreases complications of emergent tracheal intubation in the ward and intensive care unit. Anesth Analg. 2016;122:1101-7.

22. Lee BJ, Kang JM, Kim DO. Laryngeal exposure during laryngoscopy is better in the $25^{\circ}$ back-up position than in the supine position. Br J Anaesth. 2007;99:581-6.

23. Kurihara K, Kikukawa A, Kobayashi A. Cerebral oxygenation monitor during head-up and -down tilt using near-infrared spatially resolved spectroscopy. Clin Physiol Funct Imaging. 2003;23:177-81.

24. Heier T, Feiner JR, Lin J, Brown R, Caldwell JE. Hemoglobin desaturation after succinylcholine-induced apnea: a study of the recovery of spontaneous ventilation in healthy volunteers. Anesthesiology. 2001;94:754-9.

25. Holt J, Rhode E, Kines H. Ventricular volumes and body weight in mammals. Am J Physiol. 1968;215:704-15.

Publisher's Note Springer Nature remains neutral with regard to jurisdictional claims in published maps and institutional affiliations. 